\title{
Prieto Borrego, Lucía (2018), Mujer, moral y franquismo. Del velo al bikini, Universidad, Málaga, 351 págs. ISBN: 978-84-1744-906-3.
}

A modo de continuación y ampliación de un primer acercamiento publicado por Lucía Prieto Borrego ${ }^{1}$, nos encontramos ante una obra que centra su atención en el Patronato de Protección a la Mujer: Mujer, moral y franquismo. Del velo al bikini. De manera magistral y sustentada en una gran cantidad de fuentes de la propia institución, la autora confecciona una amplia radiografía del Patronato, a la vez que más adelante aplica dicha radiografía al estudio de caso de la provincia de Málaga. No es de extrañar, pues parte de su trayectoria investigadora se ha centrado en el análisis de la posguerra en Andalucía, demostrando poseer un profundo conocimiento de la provincia de Málaga y los entresijos políticos de la misma. Pero también del proyecto moralizador del franquismo, que ha abordado a través de diferentes temáticas desde la óptica de la Historia Social y la Historia de las Mujeres y del Género².

Este trabajo, por tanto, responde a la cada vez más considerable atención historiográfica que desde las corrientes citadas se dedica a indagar en el papel de las mujeres en la Guerra Civil y el franquismo y la situación de estas a lo largo de la dictadura. Concretamente, aquí presenta al Patronato como uno de los más relevantes mecanismos de represión orquestados por el régimen ${ }^{3}$, centrado en la reeducación y recuperación de aquellas mujeres que no encajaban dentro del estrecho corsé moral impuesto. O que, a tenor del cambio social que se inició a mediados de los años cincuenta y principios de los sesenta, comenzaron a transgredir los límites de la moral católica tradicional. Un análisis que viene siendo reclamado desde hace tiempo, pues se ha insistido en la necesidad de elaborar un

1. Prieto Borrego, Lucía (2006), "La prostitución en Andalucía durante el primer franquismo", Baetica. Estudios de Arte, Geografia e Historia, 28, pp. 665-687.

2. Por ejemplo: Prieto Borrego, Lucía (2016), "La copla: un instrumento para el proyecto de moralización de la sociedad española durante el primer franquismo", Arenal, 23/2, pp. 287-320.

3. González Calleja, Eduardo (1999), "Violencia política y represión en la España franquista: consideraciones teóricas y estado de la cuestión", en R. Moreno Fonseret y F. Sevillano Calero (eds.), El franquismo. Visiones y balances, Universidad, Alicante, p. 124. 
estudio sistemático de la represión específica de las mujeres durante la dictadura ${ }^{4}$.

Se trata de una institución que, si bien es mencionada en multitud de trabajos que analizan la articulación del modelo de feminidad impuesto por el régimen a las españolas y las vías y mecanismos adoptados para tal imposición, adolecía de la falta de un estudio monográfico específico. Algunos acercamientos se abordaron desde la óptica del análisis de la prostitución y la sexualidad ${ }^{5}$, pero otros aspectos en los que se detiene la autora habían pasado hasta ahora desapercibidos o habían sido tratados de forma tangencial. Otra de las virtudes de su investigación radica en el marco temporal establecido, pues abarca la evolución del Patronato desde su creación hasta los años finales de la dictadura, sacando a relucir las reconversiones y virajes que desde la propia institución se llevaron a cabo, a tenor de la legislación que se fue promulgando, pero también de cierta instrumentalización de la institución por algunos sectores de la población.

La obra se organiza en dos grandes apartados. En primer lugar, la autora realiza un examen minucioso y en profundidad sobre el Patronato de Protección a la Mujer, situando al mismo a través de la realización de una genealogía sobre los mecanismos que en España se dieron para el control de la trata de blancas. En el capítulo inicial contextualiza al Patronato dentro de la ideología de género del franquismo, sustentada en dos grandes pilares: el discurso médico-científico moderno y la Iglesia. En los siguientes capítulos muestra el desarrollo, los medios humanos y materiales, las personas y las vías a través de las cuales se ejerció el control de la población por parte del Patronato, así como los aspectos que preocupaban especialmente a la institución. Para cerrar la primera parte, que permite comprender el desarrollo del Patronato y de su proyecto, examina los presupuestos con los que contó y cómo se distribuyeron.

Ello pone de manifiesto, más allá del conocimiento establecido sobre el control moral de las mujeres que trató de ejercer la dictadura, los distintos periodos y contextos que propiciaron algunas de las concesiones en cuanto al ideal de feminidad del franquismo y permite entender los cambios legislativos y discursivos del régimen respecto a las mujeres, situando a la institución en el contexto político español de aquellos años. Por poner un ejemplo, se explica bajo qué premisas se toleró durante el periodo autárquico la prostitución bajo la doctrina del "mal menor", apoyada también por ciertos sectores de la Iglesia, mientras que se retomaba la senda abolicionista iniciada por la II República durante el desarrollismo, a consecuencia de la búsqueda de aceptación por parte de la comunidad internacional.

4. Molinero Ruiz, Carme (2005), "Historia, mujeres, franquismo. Una posible agenda de investigación en el ámbito político", en M. Ortiz Heras (coord.), Memoria e historia del franquismo. Actas del V Encuentro de investigadores del franquismo, Universidad de Castilla la Mancha, Cuenca, p. 183.

5. El más conocido seguramente sea el de Guereña, J. L. (2003), La prostitución en la España contemporánea, Marcial Pons, Madrid. 
Si nos remitimos a las fuentes presentadas por la autora, la prostitución sería constantemente achacada a la influencia del periodo republicano, tratando de establecer relación directa entre la mayor incidencia de esta y el mayor tiempo que determinadas zonas permanecieron bajo control del legítimo gobierno de la República. Pasado el tiempo, los informes trataron de minimizar el problema y, tras su prohibición oficial, maquillaron los datos como forma de mostrar el éxito del Patronato en su misión, apoyada mayoritariamente en la Iglesia. No solo en cuanto a la elaboración moral y discursiva, sino de forma material, pues muchos de los centros donde se internaba a las mujeres eran regentados y controlados por monjas. Esto, que queda evidenciado de forma suficiente en los primeros capítulos, se observa con todo lujo de detalles en la segunda parte de la obra, dedicada al estudio del caso de Málaga.

En ella, profundiza en el estudio de casos particulares a través del análisis de los expedientes personales de denuncia. En un primer capítulo nos sitúa en la paupérrima situación de Málaga en la posguerra, en la que pobreza y miseria se extendían entre la población, lo que puede ayudar a comprender que algunas mujeres recurrieran a formas extremas para la supervivencia. El Patronato tenía como misión proteger a aquellas mujeres que consideraba en riesgo de caer en la prostitución, si bien "esta facultad se proyectó de forma amplia sobre cualquier comportamiento sospechoso de inmoralidad" (p. 211). En los siguientes capítulos expone cómo se implantó en Málaga el Patronato, las facultades con las que contaba para inmiscuirse en las vidas privadas hasta tal extremo, las distintas tipologías de casos sobre los que actuó, la evolución en el discurso de la institución, así como de la provincia con su conversión en destino turístico y la preocupación por la influencia de este en la moral y la perversión de las buenas costumbres de las malagueñas.

Las idílicas condiciones descritas por el Patronato sobre la situación de sus acogidas, sobre todo en el caso de las caídas y las casas de maternidad a las que eran enviadas, se desmontan ante la evidencia de los casos específicos que incluye la autora en el texto. La profundidad en el control de la población femenina queda patente en el uso del Patronato, al menos en Málaga, como medio de coerción para las mujeres que comenzaban a trasgredir la estricta moral católica, principio sustentador del proyecto de moralización y control social del franquismo. Además, la crudeza de algunos de los testimonios proporcionados por la autora contribuye a la formación de una idea más exacta de la situación de las mujeres bajo el franquismo, respecto a un conjunto de temas insuficientemente visibilizados aún hoy en día.

En definitiva, nos encontramos ante una obra que presenta una radiografía rigurosa del Patronato de Protección de la Mujer a lo largo de su existencia como tal, y que, por lo tanto, resulta esencial para enriquecer nuestro conocimiento sobre las diversas formas de las que dispuso el franquismo para homogeneizar y controlar la conducta de las españolas, así como de censurar y reprimir todas aquellas actitudes que contravenían la moral oficial. Al mismo tiempo, permite conocer los entresijos de su trayectoria y los medios humanos y materiales de que 
se sirvió para llevar a cabo su proyecto. Por otro lado, a través de la variedad de casos individuales que aporta la autora, podemos aprehender la auténtica magnitud de la represión y control social ejercidos por la dictadura sobre las mujeres, así como la doble moral que se extendió por el país durante aquellos años. No es difícil reconocer en los testimonios aportados algunos de los prejuicios que todavía hoy en día soportan las españolas, cuestión que sitúa el tema tratado en el debate social actual, a la vez que evidencia la importancia de realizar estudios de caso que permitan comprender la situación de cada territorio.

Núria Félez Castañé 